\title{
Turbulence Induced by Storm Waves on Deep Water
}

\author{
S.Yu. Kuznetsov ${ }^{1}$, Ya.V. Saprykina ${ }^{1}$, V.A. Dulov', \\ A.M. Chukharev ${ }^{2}$ \\ ${ }^{1}$ Shirshov Oceanological Institute, Russian Academy of Sciences, Moscow, \\ Russian Federation \\ e-mail: kuznetsov@ocean.ru, saprykina@ocean.ru \\ ${ }^{2}$ Marine Hydrophysical Institute, Russian Academy of Sciences, Sevastopol, \\ Russian Federation \\ e-mail: dulov1952@gmail.com, alexchukh@mail.ru
}

\begin{abstract}
Results of laboratory and field experiments performed in November-December, 2014 to study turbulence induced by wave motion are represented. Elevations of free sea surface and fluctuations of three components of water particle velocity are synchronously measured at calm conditions when wave breaking is absent. The data is obtained in the ranges of wave and turbulence frequencies, and in the depth range from the surface to half a length of surface waves. A method for separating the measured velocity fluctuations into at a wave and two turbulence components (the one is induced by wave motions and another is a background hydrodynamic turbulence) is developed. In field experiments the bound frequency of $\sim 0.8 \mathrm{~Hz}$ had been determined. The coherence of the turbulent fluctuations and sea surface elevations sharply decreases above this frequency. Direct instrumental measurements confirmed stratification of a wave flow into a near-surface turbulent layer induced by wave motion and an underlying layer with the background hydrodynamic turbulence. The characteristics of turbulence in a near-surface layer are connected linearly with magnitude of envelope of vertical component velocity. This fact enables to attribute the turbulent fluctuations in this layer to wave-induced turbulence. Based on analysis of experiments the conclusion about existence of wave-induced turbulence in absentia other sources of turbulence such as wave breaking, wind stresses and Langmuir circulations is drawn.
\end{abstract}

Keywords: wave induced turbulence, background turbulence, field experiment, storm waves.

DOI: 10.22449/1573-160X-2015-5-22-31

(C) 2015, S.Yu. Kuznetsov, Ya.V. Saprykina, V.A. Dulov, A.M. Chukharev

(C) 2015, Physical Oceanography

Introducton. According to the definition given by A.S. Monin and R. V. Ozmidov, turbulence is a phenomenon observed in many liquid and gas flows, and is that thermodynamical and hydrodynamical characteristics of such flows (velocity, temperature, density, pressure etc.) undergo chaotic fluctuations (caused by numerous vortices of different sizes in these flows) and owing to this change from point to point and in the course of time irregularly [1]. The occurrence of the turbulent velocity pulsations of water particles in a wave flow was experimentally registered for the first time with the light-polarization method by A. A. Dmitriev and T. V. Bonchkovskaya. In their paper are represented three consecutive photos of wave propagation at the still water, showing the leading wavefront to move farther from the survey point and the greater (by height) surficial area of flow to be involved in turbulent motion [2].

The existence of laminar and turbulent mode areas in laboratory wave flow at the deep water was registered by S. V. Dobroklonsky and N. V. Kontoboytseva by means of Reynolds color jet method. Grains of paint were dropped into the water (during the disposition they left thin vertical traces), then wave generator was turned on and the observations, fixing the colored traces to keep their individuality, were performed [3]. As a result, the following facts were ascertained: turbulence is initiated in the upper flow layer with $\delta>0.021$ wave steepness; 2) subsurface turbulent layer thickness $l_{T}$ is linearly linked with wave height and length: $l_{T}=0.75 H+0.0081 \lambda$. These experiments were performed in the channel with $h=0.9 \mathrm{~m}$ depth at waves with $H=0.015-0.160 \mathrm{~m}$ height, $\lambda=0.66-1.56 \mathrm{~m}$ length and $T=0.65-1.00 \mathrm{~s}$ period. Such research was also carried out by M. Donelan. In 
his work [4] he reported that thickness of turbulence subsurface layer, according to visual estimates, had a wave height order. It is important to mention that all the above-listed conclusions are based on visual observations, not on instrumental measurements of the turbulence characteristics.

Sea upper layer turbulence and its connection with wind-generated sea waves were intensively studied in the second part of XX century and later [5 - 12]. By now, it had been revealed that waves generated turbulence, and its generation could be a result of wave breaking or of a wave motion itself. The second generation mechanism was considered main at the initial stage of marine subsurface turbulence development [5, 12]. Later, semiempirical models, where the wave breaking mechanism was considered main, were proposed $[6,10,11]$. However, over the last years an issue of wind-generated sea wave turbulence importance became urgent again [9-11]. In the work [13] it was shown that with this kind of turbulence the large-scaled circulation modeling results become more accurate. Nowadays there is no reliable expeditionary data without which it's impossible to solve above-listed ambiguities.

This work aimed to specify turbulence generation physics with non-breaking waves. The main idea of the work is conducting of parallel experiments in both laboratory conditions and in situ using new observation and measuring facilities to find the turbulence characteristics. The preliminary results, obtained in November - December, 2014 within the framework of the Russian Foundation for Basic Research project The South of Russia 14-45-01572 are shown in the present work.

Description of the experiments. Laboratory experiment was performed in November - December, 2014 in the hydraulic flume of Moscow State Academy of Water Transport. The hydraulic flume has the following characteristics: length $12 \mathrm{~m}$, width $-0.45 \mathrm{~m}$, height $-0.7 \mathrm{~m}$. Monochromatic non-breaking waves with $0.5 ; 0.7 ; 1.0 ; 1.25$ s periods and $3-6 \mathrm{~cm}$ heights by $30-40 \mathrm{~cm}$ water depth were tested. Wave heights were measured by capacitive string wave recorders with 18 $\mathrm{Hz}$ sampling rate, water particle velocity fluctuations were registered by two threecomponent Vectrino acoustic measurers (manufactured by Nortek company) with $25 \mathrm{~Hz}$ sampling rate on 16 horizons sequentially, record length amounted 4 minutes. Water flow, visualized by food color particles, during precipitation leaves a colored trace. Color traces smearing were registered by $29 \mathrm{fps}$ video survey. The parts of flume images with colored traces are shown in fig. 1.

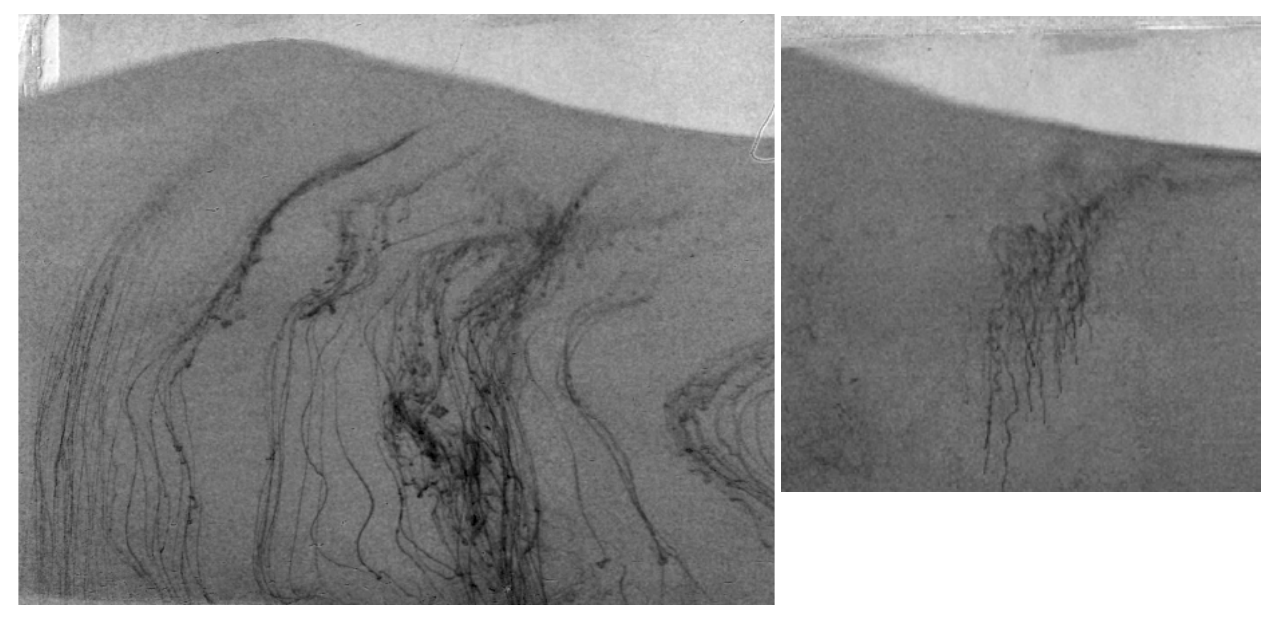

Fig. 1. Colored traces of food color particles in laboratory flume wave flow (colored particles precipitation after leaving the intensive turbulence subsurficial layer is shown on the right) 
Experiment in situ was performed in December, 2014 at the stationary oceanographic platform of the Black Sea hydrophysical research area, situated at $500 \mathrm{~m}$ distance from the coast (Katsiveli, Crimea). Depth of the measurement site is $28 \mathrm{~m}$. Three pulsating velocity components of water particles, temperature, pressure and electrical conductivity were registered by Sigma-1 measuring complex [14] synchronously with $100 \mathrm{~Hz}$ sampling rate. Electromagnetic gage of the three component velocity pulsations is a ball about $3 \mathrm{~cm}$ in diameter. On its upper pole temperature and electrical conductivity sensors are installed. Measurements were performed immersing the device to $10 \mathrm{~m}$ depth with consecutive $5 \mathrm{~min}$ stops in 17 points at $0.2-10 \mathrm{~m}$ depth range. In $6 \mathrm{~m}$ from this complex a string wave meter with $20 \mathrm{~Hz}$ sampling rate [15] was installed. Synchronously with recording, sea surface video survey aimed at wave breaking observations was performed. Meteorological parameters were registered by Davis $6152 E U$ weather station, and current mean velocities and its directions at $3,5,10$, 15, 20, $25 \mathrm{~m}$ horizons were registered by MHI-1308 measurers as a part of continuous monitoring of currents performing by Marine Hydrophysical Institute shelf hydrophysics department from the platform.

Measurements were carried out under calm conditions, with weak swell and without wave breaking (table). At the depth range within surface and $10 \mathrm{~m}$ density stratification was neutral, and current velocities were less than $20 \mathrm{~cm} / \mathrm{s}$. During the data processing special attention was focused at those records, during which the detection head of Sigma-1 complex was at $0.2-0.4 \mathrm{~m}$ depth, as at several wave troughs it was found in the air. Appropriate moments were determined by video survey. These events were also displayed at conductivity records, and that allow us to eliminate these record segments from analysis.

Basic hydrometeorogical conditions during the in situ experiments

\begin{tabular}{c|c|c|c|c}
\hline Date & Local time & $\begin{array}{c}\text { Wind velocity at } \\
\text { 22 m horizon, } \mathrm{m} / \mathrm{s}\end{array}$ & $\begin{array}{c}\text { Significant wave } \\
\text { height, } \mathrm{m}\end{array}$ & $\begin{array}{c}\text { Frequency of wave } \\
\text { height spectral } \\
\text { peak, Hz }\end{array}$ \\
\hline 13.12 .2014 & $15: 40-16: 48$ & 2.87 & 0.42 & 0.22 \\
14.12 .2014 & $09: 50-11: 43$ & 0.35 & 0.25 & 0.21 \\
15.12 .2014 & $09: 19-11: 18$ & 2.18 & 0.16 & 0.24 \\
\hline
\end{tabular}

Both laboratory and field experiments had been carried out with the absence of wind-associated stresses on the liquid surface (at least at considering calm conditions these stresses were lower, than in case of wind generation of waves). Also, there was no wave breaking, and during the in situ experiments, according the visual observations, the Langmuir circulation wasn't determined. Thus, wave motion of liquid might have been the only source of turbulence in the upper layer.

Discussing of the results. Laboratory experiments displayed obvious wave flow stratification in subsurficial layer, where the colored traces are rapidly blurred, and underlying layer with relatively long time period of their existence. In Fig. 1 waves are propagating from left to the right and colored traces are bent because of flow direction change. In the upper layer the flow, induced by waves, directs to the right, and in the lower layer appears a compensatory flow with 
reversed direction. Near the surface there is a layer, where the colored traces are completely blurred.

Video survey of the experiments allowed us to follow colored trace development with $1 / 29 \mathrm{~s}$ time resolution predetermined by frame frequency. Besides, it was clearly defined the frame which displayed the moment when color particles got on the water surface after their scattering above the flow with established wave motion. But in the next frame it's impossible to observe the particles, because colored area was immediately blurred. 15 - 30 frames later, when the particles went lower the turbulized layer, they could be observed again. Particles also left vertical colored traces. The example of such process is shown in Fig. 1 on the right. Afterwards, the traces deformed but stayed visible during $100-$ 300 frames. Thus, traces in upper layer are blurred two order as fast that in the mean level of the flume. If we assume (by analogy with the problem of twodimensional diffusion of substance, concentrated at the initial moment in the origin of coordinates (see the paper [16], where vortex line diffusion is considered)), that the trace width, at which it's no longer visible, is proportional to $\sqrt{K \tau}$ (where $K$ kinematic coefficient of horizontal turbulent diffusion, $\tau$ - time, during which the trace was visible in this horizon), this implies that $K$ value in the upper layer is 100 or more times greater than in a mean horizon. The video survey analysis shows that vertical size of intensive turbulence layer is almost $3 / 4$ of wave height. This corresponds with conclusions of the paper [3].

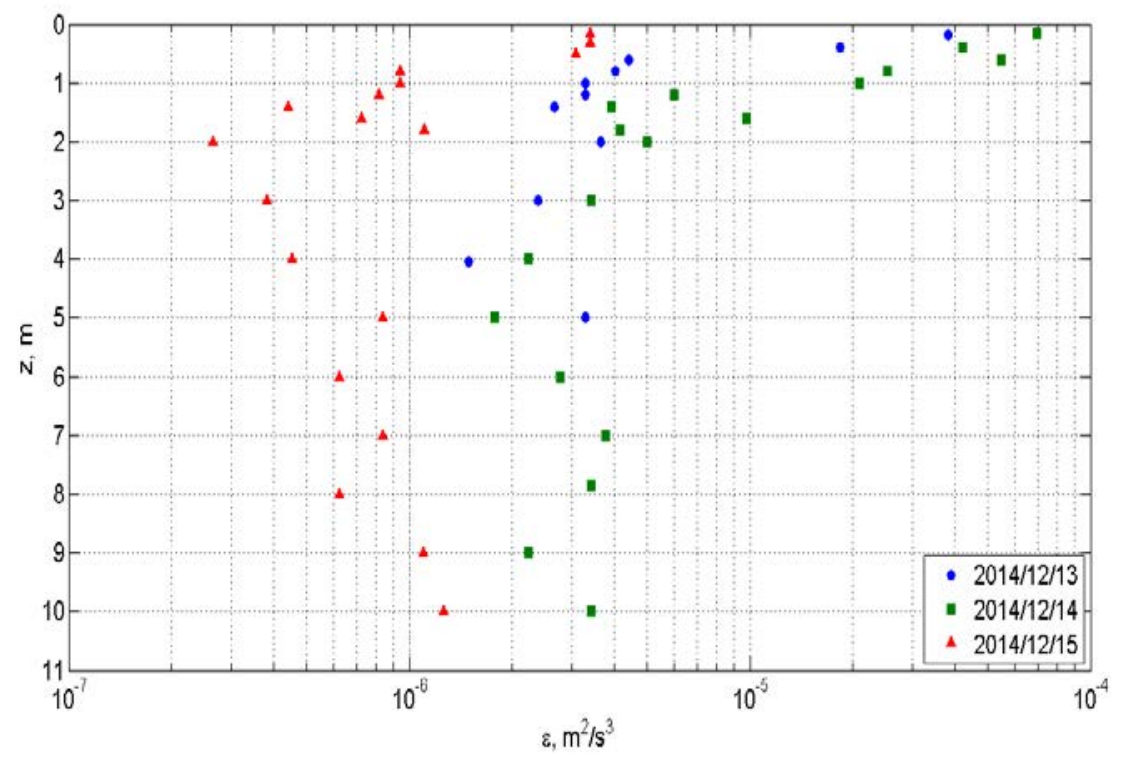

Fig. 2. Vertical profiles of dissipation rate of turbulence kinetic energy $\varepsilon$ according to the data of field experiments

Such structure of turbulent wave flow could be also observed in the natural conditions. Intensity of turbulence could be featured by dissipation rate of turbulence kinetic energy $\varepsilon$ in liquid mass unit. Vertical profiles $\varepsilon$ for all in situ experiments are shown in Fig. 2. Value of $\varepsilon$ for each measurement horizon was calculated by vertical velocity fluctuation records according to methodology given 
in the article [17], based on the Kolmogorov hypothesis about inertial range in turbulence spectrum. In the article [11] methodology details in reference to Sigma1 measuring complex data are described. Fig, 2 depicts that in the expeditionary conditions the wave flow layering at upper turbulent area and lower area with background hydrodynamic turbulence also takes place. In the water column $\varepsilon$ value changes insignificantly, but near the surface it could be clearly observed a layer with more intensive turbulence. The width of this layer is almost equal to the height of significant waves (table).

Now it's necessary to consider the relationship between wave and turbulence parameters relying on field data. In Fig. 3 the spectra of water-surface elevation $S_{\zeta}$, pressure $S_{h}$ and three components of water particle velocity $S_{u}, S_{v}, S_{w}$ for the experiment (December 13, 2014) are given. Spectra are constructed in accordance with Welch method (by partition of chronograms at overlapped segments, multiplying of segments by the Hann time window, Fourier transform and following averaging of spectral functions by all segments). During the field experiment the windows with $0.1 \mathrm{~Hz}$ spectral resolution were used, number of freedom degrees of analyzed spectral estimations was equal to 34. The same methodology and parameters were used in this paper during cross-spectral and bispectral analysis.

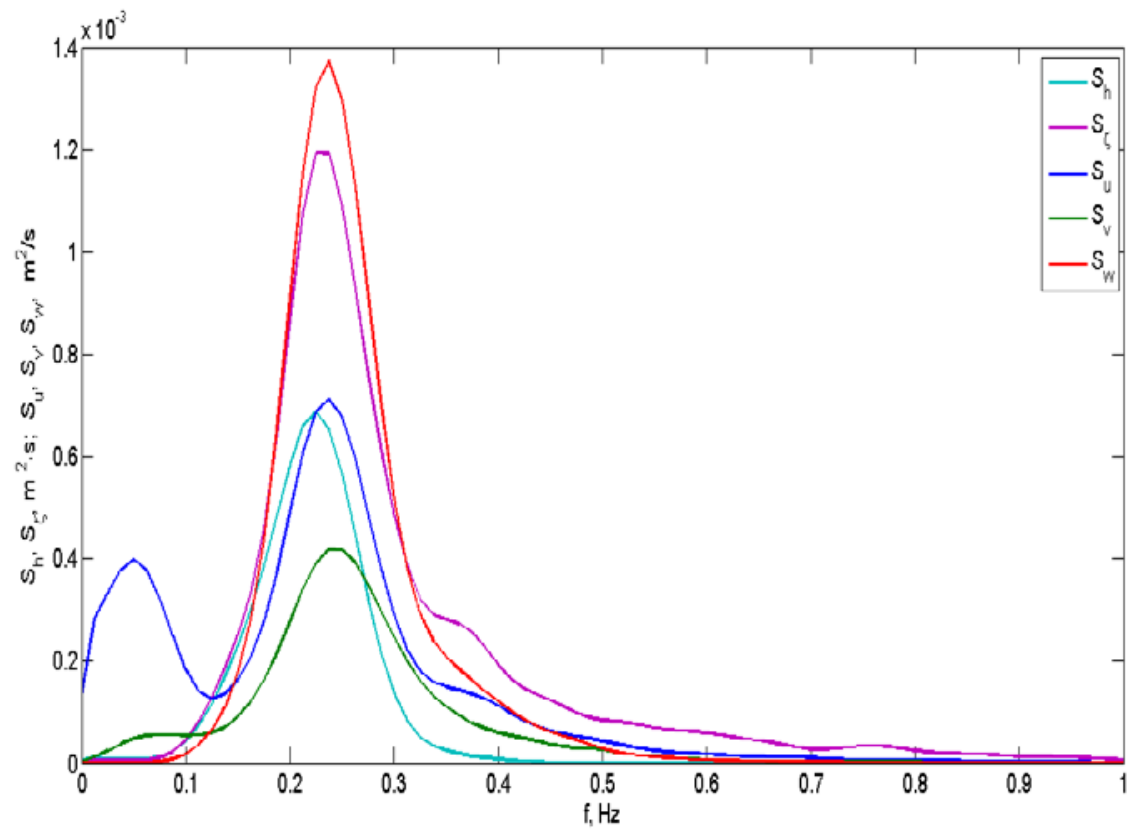

Fig. 3. Typical spectra of water-surface elevations $S_{\zeta}$, pressure $S_{h}$ and three components of water particle velocity $S_{u}, S_{v}, S_{w}$, measured at $1.4 \mathrm{~m}$. depth during the experiment (December 13, 2014)

During the instrumental measurements of small-scale turbulence in wave flow arises the problem of turbulent motion differentiation on the background of irregular wave motion. Relating to progressive flow it could be solved naturally: random fluctuations on the background of mean current are considered to be 
turbulence. In our case, we'll follow the approach presented earlier in the paper [18] in appendix to the data obtained at Bulgarian coast of the Black Sea. According to the calculated values of coherence function between free surface elevation and velocity fluctuations in the water it's obvious, that there is no linear relationship between them above a certain $f_{B}$ frequency. Bispectral analysis of these values also showed almost complete absence of quadratic nonlinear relation for frequencies above $f_{B}$. In the reference paper this allowed to include water particle velocity fluctuations with frequencies more, than $3-4$ frequencies of wave spectrum maximum to the turbulent motion.

In Fig. 4 the coherence functions between the values $u, v, w, \zeta$ for the records of December 13, 2014, which show a sharp decrease of coherence in the frequencies above $0.8 \mathrm{~Hz}$, are given. At the present frequency range a bispectral analysis also showed no quadratic relationship between signals. The calculation results for other records on different horizons allowed us to conclude that $0.8 \mathrm{~Hz}$ frequency could be taken as boundary frequency, i.e. at higher frequencies the motion could be certainly considered as turbulent. Therefrom, we have separated a turbulent component from velocity fluctuation records by means of Fourier filtering with $0.8 \mathrm{~Hz}$ boundary frequency.

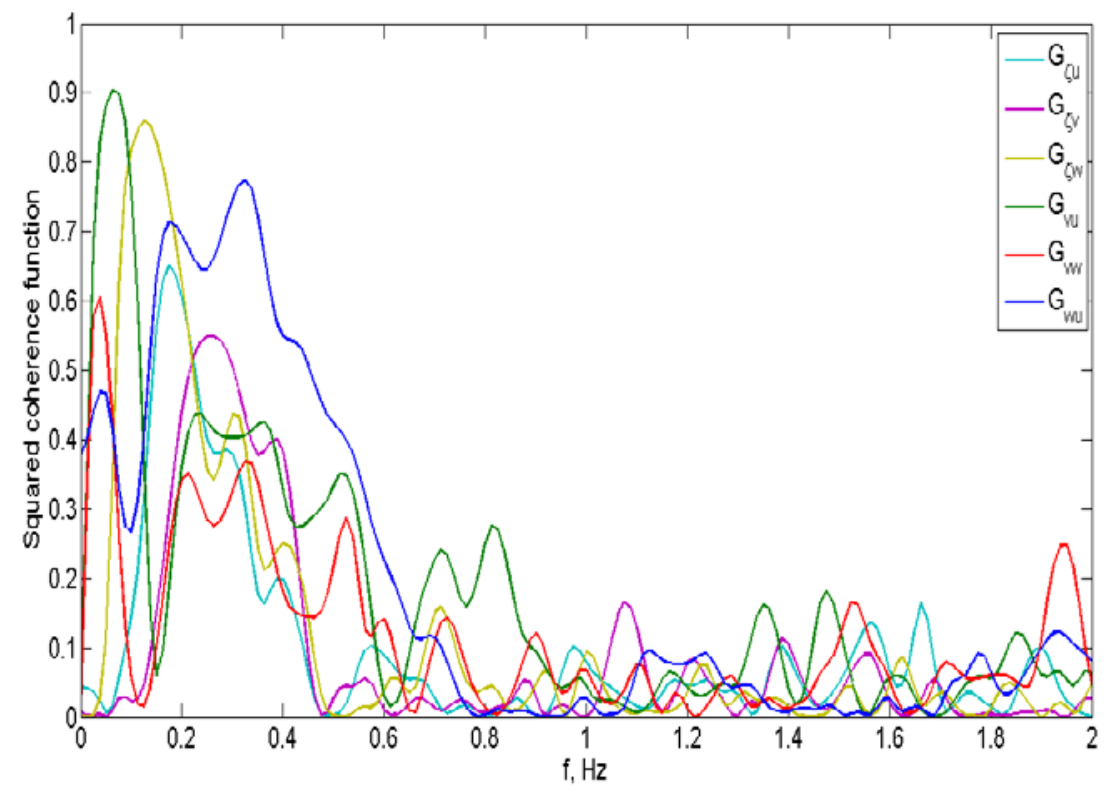

Fig. 4. Typical squared coherence functions between three components of water particles velocity measured at $1.4 \mathrm{~m}$ depth during the experiment (December 13, 2014) and also between these components and the free surface elevations

Possibility of this boundary frequency usage is also confirmed by changing the spectrum slope of water particles vertical velocity fluctuations. The example of spectrum, constructed on a logarithmic scale, is shown in Fig. 5. The spectrum slope in the frequency range above the spectral peak in $0.8 \mathrm{~Hz}$ boundary frequency changes from value -5 (where dominate the wave motion) to -3 (where the motion 
is purely turbulent). It is necessary to note, that the spectrum of free surface elevations, shown in Fig. 5 has - 4 slope throughout the range of frequencies.

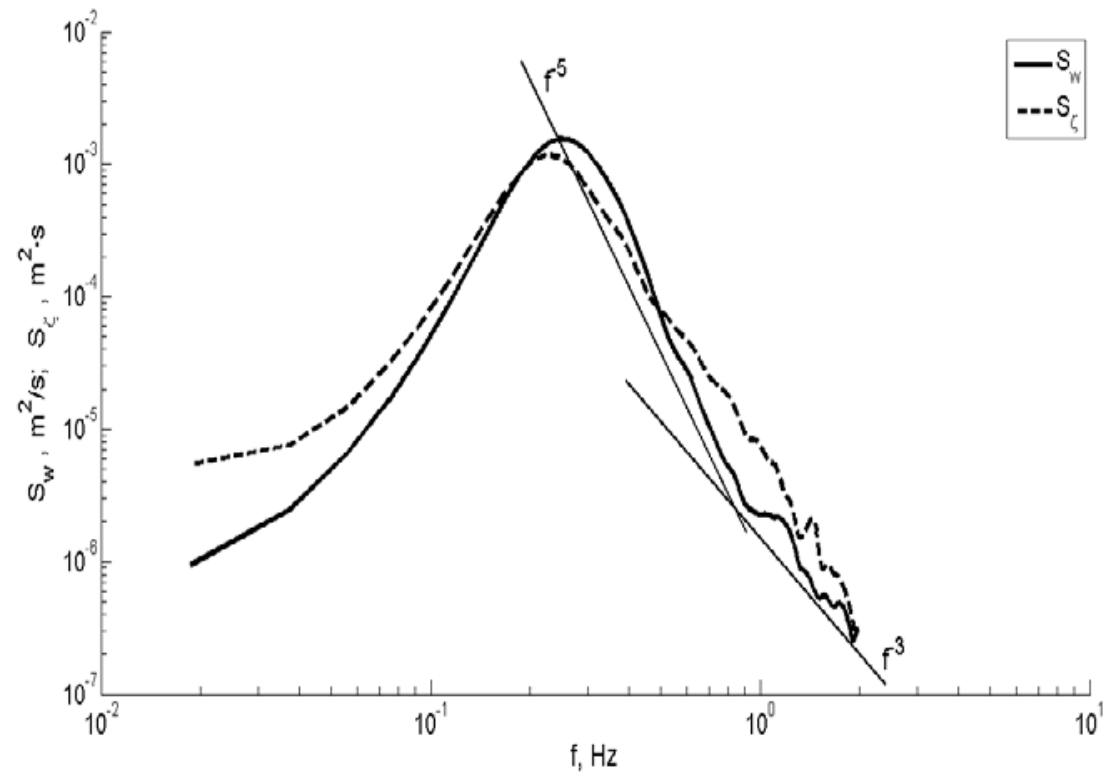

Fig. 5. Change in the spectrum slope of the vertical velocity component $S_{w}$ from -5 to -3 during the transition from wave to turbulent motion (boundary frequency $-0.8 \mathrm{~Hz}$; the spectrum slope of free surface elevation $S_{\zeta}$ remains constant and equal to -4)

Now we should demonstrate the separation of background hydrodynamic turbulence and turbulence, induced by waves, both in space and frequency. For this purpose there were calculated the coherence functions between the wave component envelope of water particles vertical velocity, calculated by Hilbert transform, and value chronograms of instantaneous water particle kinetic energy $E_{t}$, calculated as the sum of squares of three water particle velocity turbulent components. Changing of these coherence functions is shown in Fig. 6 and it demonstrates the absence of linear relationship between the envelope fluctuations and fluctuations of turbulent kinetic energy at depths greater than $2 \mathrm{~m}$. These facts allow us to refer the turbulent fluctuations in the upper 2-m water layer to the induced waves, and measured below - to the background hydrodynamic turbulence. Turbulence intensity $I$, calculated as a square root of the time-averaged kinetic energy of turbulence, rapidly decays with depth in the upper layer in accordance with the wave motion attenuation with depth, and remains approximately constant in the lower horizons (as it is shown in Fig. 7).

The conclusion about the turbulence partition into background and waveinduced turbulence is confirmed by the analysis of the Reynolds stress $\tau$ tensor components, calculated by the termwise multiplying of the corresponding series of water particles velocity turbulent components. Cross-spectral analysis demonstrated a high coherence (in some cases up to 0.7) between the vertical component of water particles velocity and tensor components of the Reynolds 
stress $\tau$. The typical form of the coherence function is shown in Fig. 8. Coherence disappears at depths greater than $2 \mathrm{~m}$.

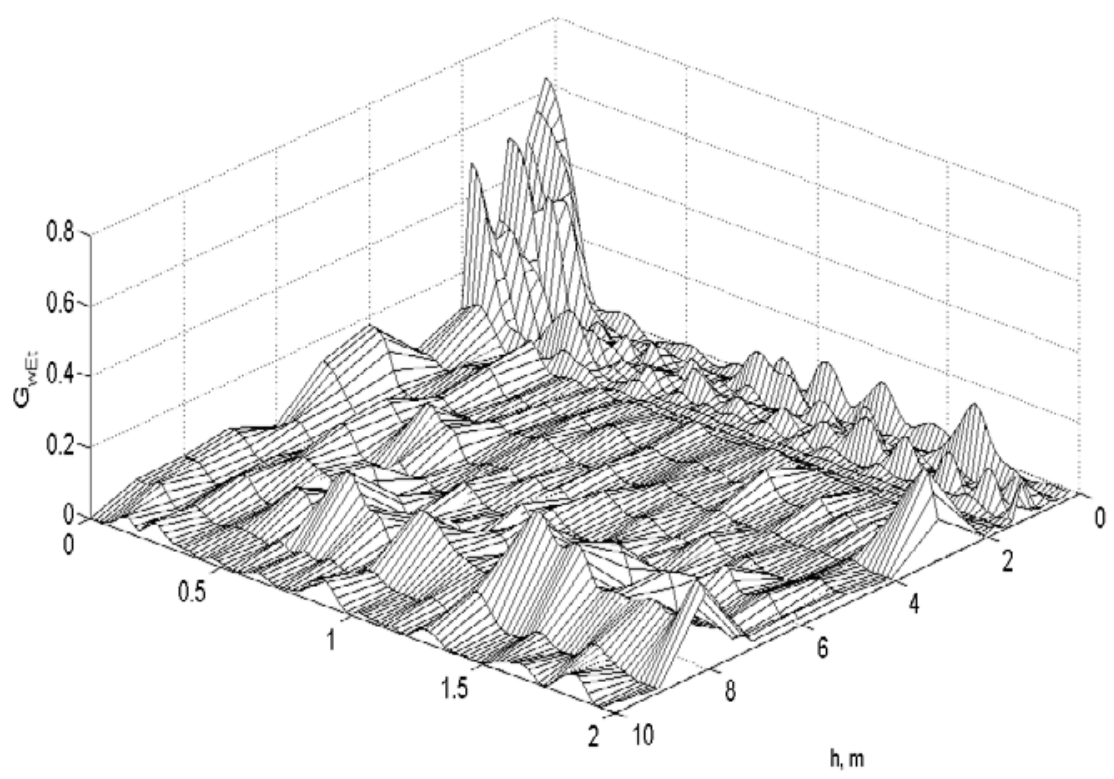

Fig. 6. The change of squared coherence function between the wave component envelope of water particles vertical velocity and the kinetic energy of turbulence $E_{t}$ with the depth and frequency (during the experiment on December 14, 2014)

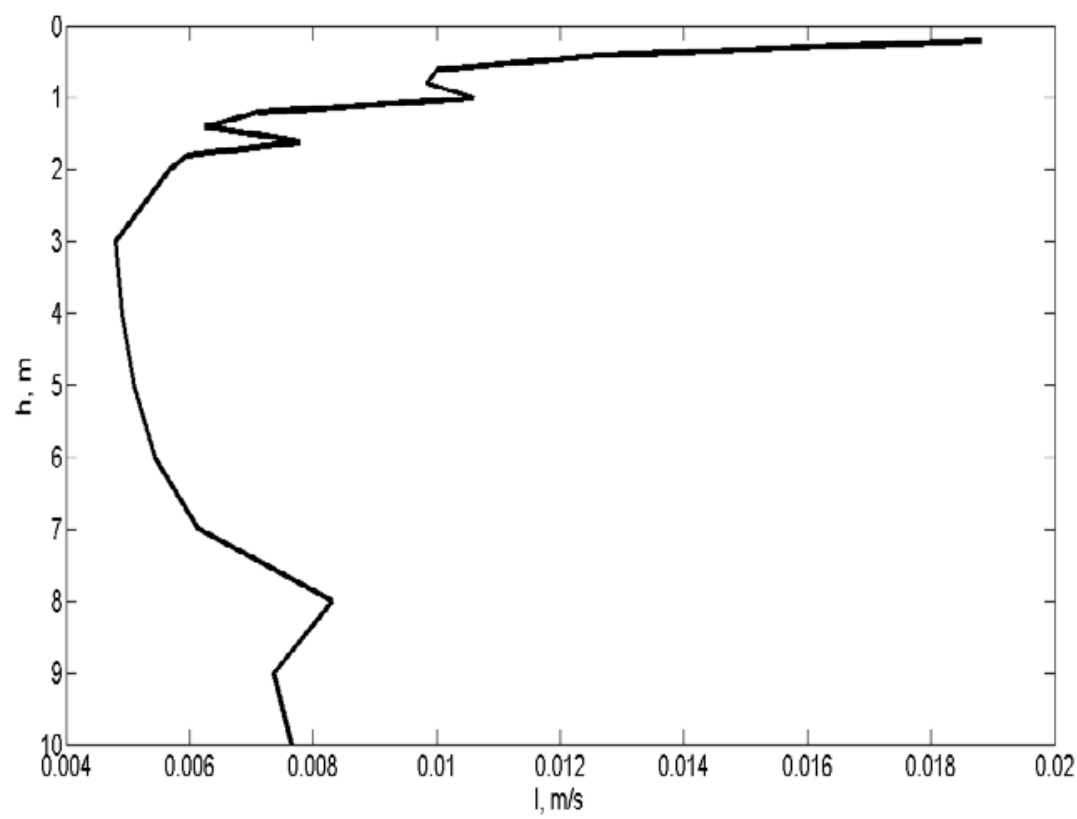

Fig. 7. Change of the intensity $I$ of the water particles velocity turbulent fluctuations with the depth (during the experiment on December 14, 2014)

PHYSICAL OCEANOGRAPHY NO. 5 (2015) 


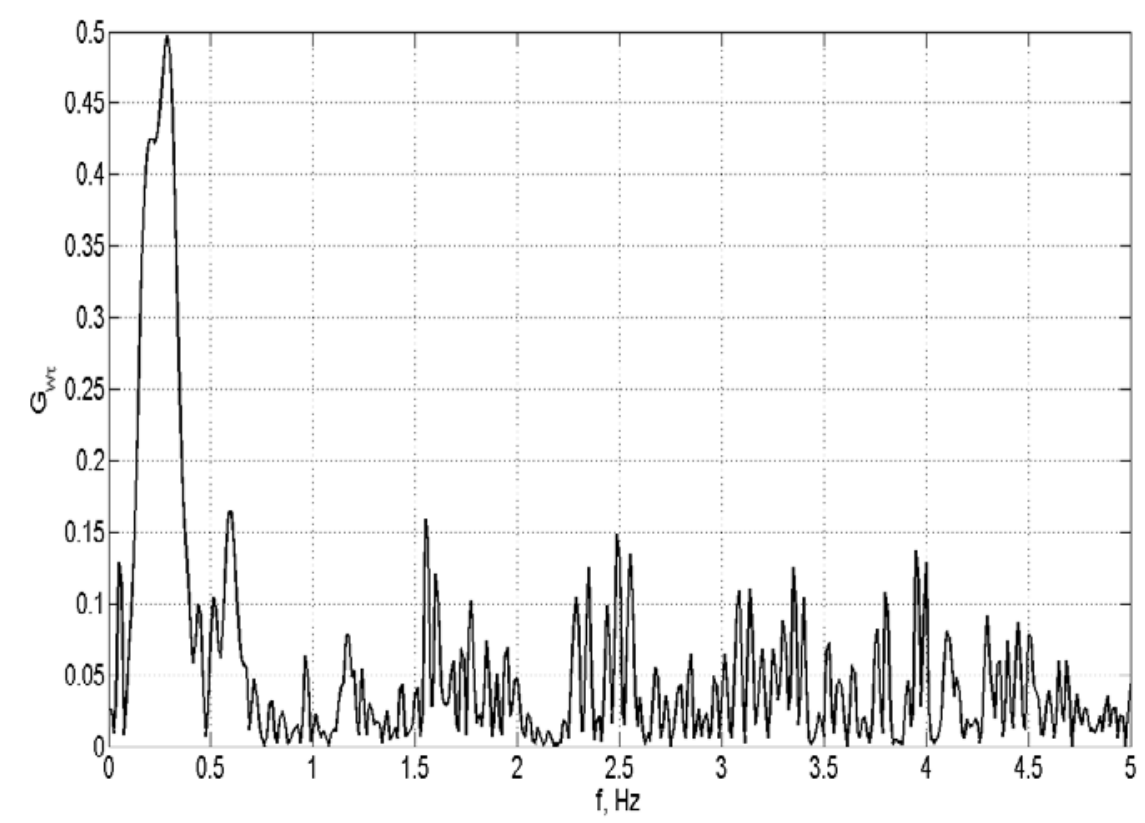

Fig. 8. The squared coherence function between the components of the Reynolds stress $\tau$ tensor and the vertical component of water particles velocity measured at the depth of $1.6 \mathrm{~m}$ (during the experiment on December 14, 2014)

Conclusions. The direct instrumental measurements in situ, as well as visualization of the turbulent diffusion in a laboratory flume using the colored traces, confirmed the separation of the wave flow into the subsurface layer with the intensive turbulence and the underlying layer with substantially lesser background hydrodynamic turbulence intensity. The separation of measured velocity fluctuations into the wave and turbulent components was performed. Natural irregularity of the sea waves, manifested in the form of the wave group structure, is used for the separation of turbulence into the wave-induced and the background hydrodynamic turbulence. The characteristics of the upper layer turbulence are linearly related to the envelope value of wave component of water particles vertical velocity, which allow us to consider the turbulence in the upper layer as the waveinduced turbulence. The analysis of the experiment data suggests the presence of wave-induced turbulence with absence of its other possible sources - wave breaking, wind stresses and the Langmuir circulation.

Acknowledgements. The authors are grateful for the mean currents data given by V. V. Zima and A. S. Kuznetsov (MHI). The research was carried out under the financial support of Russian Foundation for Basic Research, The South of Russia project № 14-45-01572.

\section{REFERENCES}

1. Monin, A.S., Ozmidov R.V., 1978, "Turbulentnost' v okeane [Turbulence in the ocean]”, Okeanologiya. Fizika okeana, vol. 1, Gidrofizika okeana, Moscow, Nauka, pp. 148-207 (in Russian). 
2. Dmitriev, A.A., Bonchkovskaya, T.V., 1953, "K voprosu o turbulentnosti v volne [On the issue on the turbulence in a wave]”, Dokl. AN SSSR, vol. 91, no. 1, pp. 31-33 (in Russian).

3. Dobroklonskii, S.V., Kontoboitseva, N.V., 1973, "Eksperimenty po opredeleniyu tolshchiny turbulentnogo sloya $v$ volnakh monokhromaticheskogo tipa [Experiments on turbulent layer detection in monochromatic type waves]", Izv. AN SSSR. Fizika atmosfery i okeana, vol. 9, no. 2, pp. 210-212 (in Russian).

4. Donelan, M.A., 1987, “The effect of swell on the growth of wind waves', Johns Hopkins APL Technical Digest., vol. 1, pp. 18-23.

5. Kitaigorodskii, S.A., Lumley, J.L., 1983, "Wave turbulence interactions in the upper ocean. Part I: The energy balance of the interacting fields of surface wind waves and wind-induced three-dimensional turbulence”, J. Phys. Oceanogr., vol. 13, no. 11, pp. 1977-1987.

6. Craig, P.D., Banner, M.L., 1994, "Modelling of wave-enhanced turbulence in the ocean surface layer”, J. Phys. Oceanogr., vol. 24, no. 12, pp. 2546-2559.

7. Drennan, W.M, Donelan, M.A. \& Terray, E.A. [et al.], 1996, "Oceanic turbulence dissipation measurements in SWADE”, J. Phys. Oceanogr., vol. 26, no. 5, pp. 800-815.

8. Kudryavtsev, V., Shrira, V., Dulov, V. [et al.], 2008, “On vertical structure of wind-driven sea surface currents”, J. Phys. Oceanogr., vol. 38, no. 10, pp. 1-2144.

9. Babanin, A.V., 2006, “On a wave-induced turbulence and a wave-mixed upper ocean layer”, Geophys. Res. Lett., vol.33, L20605, 6 p., doi:10.1029/2006GL027308.

10. Dai, D., Qiao, F. \& Sulisz, W. [et al.], 2010, “An experiment on the nonbreaking surfacewave-induced vertical mixing”, J. Phys. Oceanogr., vol. 40, no. 9, pp. 2180-2188.

11. Chukharev, A.M., 2013, "Model' turbulentnosti so mnogimi vremennymi masshtabami dlya pripoverkhnostnogo sloya morya [Multitime scale model of turbulence in the sea surface layer]”, 2013, Izv. RAN. Fizika atmosfery i okeana, vol. 49, no. 4, pp. $439-449$ (in Russian).

12. Efimov, V.V., 1981, "Dinamika volnovykh protsessov $v$ pogranichnykh sloyakh atmosfery $i$ okeana [Dynamics of the wave processes in the boundary sea and ocean layers]", Kiev, Naukova Dumka, 256 p. (in Russian).

13. Qiao, F., Yuan, Y. \& Ezer, T. [et al.], 2010, “A three-dimensional surface wave-ocean circulation coupled model and its initial testing”, Ocean Dyn., iss. 5, pp. 1339-1355.

14. Samodurov, A.S., Dykman, V.Z. \& Barabash, V.A. [et al.], 2005, “Izmeritel'nyy kompleks "Sigma-1" dlya issledovaniya melkomasshtabnykh kharakteristik gidrofizicheskikh poley $v$ verkhnem sloe morya ["Sigma-1” measuring equipment for research of small-scale features of hydrophysical fields in the sea upper layer]”, Morskoy Gidrofizicheskiy Zhurnal, no. 5, pp. 60-71 (in Russian).

15. Malinovskii,V.V., Dulov, V.A. \& Korinenko, A.E. [et al.], 2014, “Kompleks apparatury dlya podsputnikovykh izmereniy so statsionarnoy okeanograficheskoy platformy $v$ Katsiveli [Set of the equipment for sub-satellite measurements from the stationary oceanographic platform in Katsiveli]", Monitoring pribrezhnoy zony na Chernomorskom eksperimental'nom podsputnikovom poligone, Sevastopol, MGI NAN Ukrainy, pp. 128-149 (in Russian).

16. Lavrentyev, M.A., Shabat, B.V., 1973, "Problemy gidrodinamiki i ikh matematicheskie modeli [Problems of hydrodynamics and their mathematical models]", Moscow, Nauka, 416 p. (in Russian).

17. Stewart, R.W., Grant, H.L., 1962, "Determination of the rate of dissipation of turbulent energy near the sea surface in the presence of waves”, J. Geophys. Res., vol. 67, pp. 31773180 .

18. Kuznetsov, S.Yu., Dachev, V.Zh. \& Speranskii, N.S., 1992, "Nelineynye volny $i$ turbulentnost' $v$ beregovoy zone morya [Non-linear waves and turbulence in the coastal area]”, Okeanologia BAN, vol. 21, pp. 3-13 (in Russian). 